\title{
MRI and Technetium-99m Hexamethylpropylene Amine Oxime Labeled Leucocyte Scintigraphy in the Diagnosis and Differentiation between Acute Osteomyelitis and Neuroarthropathy in the Diabetic Foot
}

\author{
REEM H. BASSIOUNY, M.D.; GEHAN G. ALI, M.D. and MONA Y. HEMIMY, M.D.
}

The Department of Radiodiagnosis, Faculty of Medicine, Ain Shams University

\begin{abstract}
Background: Soft tissue and bone infection and neuro osteoarthropathy involving the foot are the most common long-term complications of diabetes mellitus, implying a serious impairment in quality of life for patients in the advanced stages of the disease. Both pathologies often coexist and differentiating between them is crucial because the management may differ substantially. Misdiagnosis may result in high morbidity for the patient such as unnecessary limb amputation. Diagnosis is largely based on clinical signs supplemented by various imaging modalities such as radiography, MR imaging, and hybrid imaging techniques such as F-18 fluorodeoxyglucose-positron emission tomography and nuclear imaging studies.
\end{abstract}

Aim of Study: The aim of this study is to evaluate the diagnostic value of MRI and technetium-99m Hexamethylpropylene Amine Oxime (HMPAO) labeled leukocyte scintigraphy in the diagnosis and differentiation between acute osteomyelitis and neuroarthropathy in the diabetic foot.

Patients and Methods: The study included 35 patients (20 men and 15 women) aged $62 \pm 8.8$ years having diabetes mellitus and a total of 43 clinically suspicious infection sites. The basic exploration included standard radiography, threephase bone scintigraphy and 99mTc-HMPAO Leucocyte Scan (HMPAO-LS) and pre and post contrast enhanced MRI. 16 bone and 10 soft tissue biopsies were obtained from ulceration sites. Clinical follow-up as well as scintigraphy and MRI performed 4 months after initial diagnosis and 1 month after antibiotic withdrawal were performed in suspected osteomyelitis cases.

Results: Among the 43 sites, 23 sites were finally diagnosed as osteomyelitis. No osteomyelitis was present at 20 sites, of which 9 sites were diagnosed as cellulitis and 11 as neuropathic ulcers based on combined clinical, imaging, pathologic findings and follow-up. The sensitivity and specificity of MRI were (95\% and $85 \%$ ) and of Labeled leucocyte scanning were $(87 \%$ and $90 \%)$ respectively.

Correspondence to: Dr. Reem H. Bassiouny, The Department of Radiodiagnosis, Faculty of Medicine, Ain Shams University
Conclusion: The combined use of 99mTc-HMPAO-LS and MRI yielded higher diagnostic efficacy in diabetic foot related complications.

Key Words: Diabetes mellitus - Diabetic foot - MR imaging - Labeled leucocyte scintigraphy - Neuropathic osteoarthropathy - Osteomyelitis.

\section{Introduction}

DIABETES Mellitus (DM) is a multi-systemic disease with a current worldwide prevalence estimated as $5.1 \%$ and predicted to reach $7.7 \%$ by 2030 [1]. It is mainly a neurovascular disease with special predilection to the musculoskeletal system, particularly the foot [2]. Diabetic foot is prone to skin ulceration because of associated risk factors such as microangiopathies, peripheral neuropathies and also altered biomechanics. Infection is common in diabetic foot with ulceration due to direct spread from skin ulcer [3]. An altered immune response in diabetic patients (i.e. defective phagocytosis and microbicidal activity of granulocytes) contribute to the development of infectious foot complications [4]

The clinical diagnosis and treatment of infected or potentially infected foot is difficult because local symptoms are usually diminished as a result of neuropathy, vascular disease and defective immunity. Not all diabetic patients with foot infection are febrile and one cannot differentiate whether the signs of inflammation are due to cellulitis or osteomyelitis. Helpful clinical features that suggest the development of osteomyelitis are an ulcer with a cross sectional area greater than $2 \mathrm{~cm}^{2}$ extending down to bone and an ESR $>70 \mathrm{~mm} / \mathrm{h}$. In addition palpation of bone in the depth of an infected pedal ulcer is strongly correlated with the presence of osteomyelitis. Definite diagnosis of osteomyelitis 
require bone culture and histology and optimum treatment often require surgical debridement or resection, and/or prolonged antibiotic therapy $[\mathbf{5 , 6}]$

Neuroarthropathy (Charcot joint) is another major complication in uncontrolled diabetes: $\mathrm{Pe}$ ripheral neuropathy causes reduced perception of trauma, and peripheral vascular disease results in ischemia, causing poor healing, joint instability, deformity, and increased new bone formation. Progressive arthropathy with cartilage damage, erosions and subchondral cysts is also a feature of this condition. The tarsometatarsal (Lisfranc) joints are typically affected in neuropathic osteoarthropathy, leading to a collapse of the longitudinal arch and increased load bearing on the cuboid, ultimately causing a rockerbottom deformity [29].

The early and accurate diagnosis of diabetesrelated foot complications can help reduce the incidence of infection-related morbidities, the need for and duration of hospitalization, and the incidence of major limb amputation. Imaging studies including conventional radiography, nuclear medicine scintigraphy and contrast enhanced magnetic resonance imaging, are the main procedures currently in use for the evaluation of diabetes-related foot complications [25]

This study was performed to determine the role of labeled leucocyte scanning, combined with MRI in the diagnosis of diabetic foot related complications particularly in the differentiation between acute osteomyelitis and active Charcot or chronic Charcot with or without superimposed osteomyelitis.

\section{Patients and Methods}

\section{Patients:}

This prospective study included 35 patients (20 men and 15 women) age (mean \pm SD) $62 \pm 8.8$ years (range 40-77 years); with diabetes mellitus (type $1, n=22$, type $2, n=13$ ) who presented to the Radiology Department of Ain Shams University Hospitals with complicated diabetic foot between March 2014 and June 2017. The study was approved by the Ethical Committee of Ain Shams University Hospitals on March 2014. Written consent for participation in the study was obtained from patients themselves or by primary degree relatives. Laboratory investigations e.g C-Reactive Protein (CRP) levels, ESR and White Blood Cell (WBC) count were performed for all patients.

Inclusion criteria included all patients with suspected bone or joint infection from a single or multiple foot ulcers or neuropathic joints. Patients with previous vascular or foot surgery during the last six months with persistent ulcers, patients with acute limb-threatening infection (i.e., extensive necrotizing fasciitis) or systemic infection since these clinical presentations are medical emergencies and require immediate antibiotic therapy and patients with contraindications to MRI e,g pacemakers, implants etc., were all excluded from the study population.

Initial imaging evaluation included standardized dorsi-plantar and lateral weight-bearing radiographs on the day of admission and weekly thereafter for at least three monthes when they were negative or indeterminate. Three-phase bone scintigraphy, was performed 24 hours after plain films, and $99 \mathrm{mTc}-$ HMPAO labeled leucocyte scintigraphy (HMPAOLS) was performed within a 2-day interval. Pre and post contrast enhanced MRI was performed within maximum 4 days of the initial radiographic investigation.

\section{Imaging protocol:}

Magnetic resonance imaging:

MRI was performed on a Siemens Vision 1.5T (Siemens AG, Healthcare sector, 91052 Erlangen, Germany) using a knee coil. Precontrast imaging included conventional spin echo T1W (SE TR/TE: 400/11), T2W (TR/TE: 4200/96) and PD fat suppressed (TR/TE: 2550/35); FOW: 180; matrix 256 256 , slice thickness $4 \mathrm{~mm}$ in sagittal, and axial orientation. Fat suppressed Turbo inversion recovery (TIRMTR/TE: 5349/71; FOV: 200; matrix 256 256, slice thickness $4 \mathrm{~mm}$ ) in sagittal and coronal orientations was also obtained. After the injection of $0.1 \mathrm{mmol} / \mathrm{kg}$ Gadolinium Diethylenetriaminepentaacetic acid (Gd-DTPA), T1 SE and PD Fat sat sequences in sagittal and axial orientation were repeated.

\section{Radionuclide studies:}

All images were obtained using a Siemens Orbiter gamma camera equipped with a collimator. Three-phase bone scintigraphy was performed using 20mCi Tc 99m Methylene Diphonate (MDP). Immediately after injection, dynamic images of the feet (1s/frame) were obtained for $1 \mathrm{~min}$. Five minutes after the injection the blood-pool phase at $60 \mathrm{~s} /$ frame for $5 \mathrm{~s}$. After $4 \mathrm{~h}, 500000$-count static images of the feet (plantar, lateral and medial views) were obtained for 3P-MDP.

The labeling procedure of the leucocytes was as follows: $6 \mathrm{ml}$ of citric acid dextrose solution and $9 \mathrm{ml} \mathrm{6 \%}$ hydroxyl-ethyl-starch were drawn into a $60-\mathrm{ml}$ sterile plastic syringe. Samples $(35 \mathrm{ml})$ of the patient's blood were withdrawn into the syringe 
and mixed gently. The erythrocytes were allowed to settle for 30-60min. Leucocyte-platelet-rich plasma was obtained by drawing blood into a sterile vacuum tube and centrifuging for $10 \mathrm{~min}$ at $150 \mathrm{~g}$ for leucocyte separation. Leucocytes were labeled with $450 \mathrm{MBq}(10 \mathrm{mCi})$ of freshly prepared Tc $99 \mathrm{~m}$ hexamethylpropyleneamine (HMPAO), incubated at room temperature for $10 \mathrm{~min}$ and centrifuged at $150 \mathrm{~g}$ for $5 \mathrm{~min}$. The labeled cells were re-suspended in saline and re-injected intravenously. Early dynamic images of the body part of concern immediately following IV injection of Tc 99m HMPAO leucocytes were taken. Whole body scan and static spot views of the part of interest were obtained at 30 minutes, 2, 4, and 24 hours post injection. Special care was taken to place the patients in the same position as for bone scintigraphy. The ulcer dressing was carefully changed between the leucocytes injection and the first images acquisition.

\section{Image interpretation:}

Three radiologists with at least five years experience in musculoskeletal imaging and bone scintigraphy independently interpreted the images. HMPAO scans were considered positive for osteomyelitis when there was an abnormal accumulation of leucocytes in a zone concordant with the area of uptake on bone scintigraphy. These scans were considered negative for osteomyelitis in the presence of abnormal accumulation of leucocytes in a zone not concordant with the area of uptake on bone scintigraphy (soft-tissue infection) or when no leucocyte accumulation was observed (no infection or aseptic inflammation).

\section{Histopathology:}

All included patients underwent histopathological examination of tenosynovium and bone tissue of adjacent area of ulcer. Follow-up scintigraphy and contrast enhanced MRI 4 months after initial diagnosis and 1 month after antibiotic withdrawal were performed in all cases.

The final diagnosis was based on histopathological results in 27 infection sites and on clinical and radiological follow-up findings following antibiotic therapy in 16 sites.

Histopathological diagnosis of osteomyelitis was based on the presence of osteonecrosis and infiltration with leucocytes or chronic inflammatory cells such as lymphocytes or plasma cells.

\section{Statistical analysis:}

The sensitivity and specificity rates of MRI and of bone scintigraphy were calculated independently and in combination. Positive [True Positive
(TP) or False Positive (FP)] and negative \{True Negative (TN) or False Negative (FN) $\}$ results for osteomyelitis were concluded if histopathologic results were positive or negative respectively in cases where bone biopsies were taken. The remaining ulcer sites were considered positive for osteomyelitis if significant clinical improvement and total resolution of imaging findings occurred following empirical antibiotic therapy. The weighted kappa was evaluated to assess inter-reader agreement. Finally disagreement was resolved by consensus to define the [True Positive (TP) or False Positive (FP)] and [True Negative (TN) or False Negative (FN)] results by imaging.

\section{Results}

The characteristics of the 20 male $(57 \%)$ and 15 female (43\%) patients were as follows: Duration of diabetes $15.8 \pm 8.7$ years (range 1-34 years); duration of foot ulcers $4.1 \pm 3.2$ months (range 0.5 12 months); ESR $68 \pm 25 \mathrm{~mm} / \mathrm{h}$ (range $37-100 \mathrm{~mm} / \mathrm{h}$ ); CRP $7.17 \pm 5.66 \mathrm{mg} / \mathrm{dl}$ (range $1-25.3 \mathrm{mg} / \mathrm{dl}$ ); serum creatinine $92 \pm 91.9 \mathrm{~mol} / \mathrm{l}$ (range $62-115 \mathrm{~mol} / \mathrm{l}$ ); WBC count 11 022 $\pm 5131 / \mathrm{mm}$ (range 5020-31880/mm.

On MRI, ulcers typically appeared as focal skin interruptions with elevated margins and associated soft tissue inflammatory changes. Unlike callus, ulcers appeared as hyperintense areas on T2W images and showed intense peripheral enhancement on post contrast images due to granulation tissue at base of ulcers. Bone biopsies were obtained from 16 ulceration sites suggested as osteomyelitis by both modalities and could not be taken from the remaining sites because of technical difficulties.

23 sites were finally diagnosed as osteomyelitis: 14 on the basis of combined imaging modalities (MRI and scintigraphy) and confirmed by histopathology, 9 sites were diagnosed by both imaging modalities and experienced improvement on clinical and radiological follow-up after empirical antibiotic therapy. MRI and labeled leucocyte scanning showed findings of osteomyelitis in two additional ulcer sites, both of which were excluded by histopathology (false positive for both modalities). In one additional site, MRI suggested osteomyelitis, however no corresponding accumulation of leucocytes was detected in this site concordant with bone scan and histopathology showed no evidence of inflammatory cells nor osteonecrosis (false $+v e$ for MRI).

Two locations with negative labeled leucocyte scanning were proved to be osteomyelitis by progressive deterioration clinically and on subsequent 
radiological follow-up (2 false ve). A solitary site was suspected clinically as infection, however it showed no significant enhancement on MRI nor leucocyte accumulation by Tc99m HMPAO labeled WBC scanning and proved to be osteomyelitis by histopathology (false negative for both modalities).
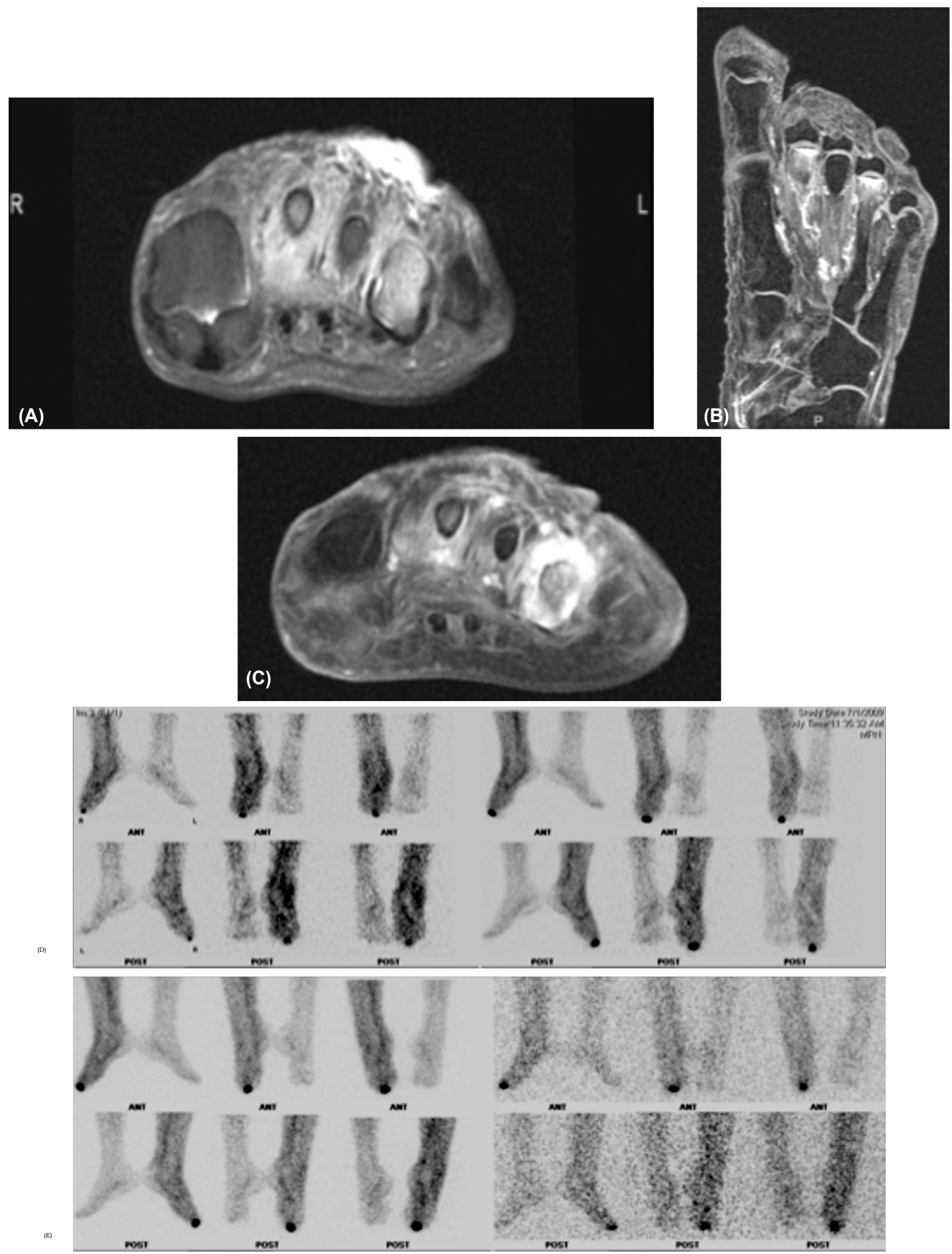

Fig. (1): Forefoot ulcer associated with 2nd and fourth metatarsal heads osteomyelitis in a diabetic patient; axial (A), and coronal (B) T2W fat suppressed images showed an ulcer in the dorsum of the foot as evidenced by superficial skin discontinuity and diffuse hyperintensity of the surrounding subcutaneous tissue. Abnormal bone marrow signal is seen at the heads of 2 nd and 4th metatarsals better appreciated at coronal images. Contrast enhanced PD fat suppressed images (C) Showed abnormal soft tissue and marrow enhancement. (D) and (E) Static 30min, 2,4 , and 24 hours labeled leucocyte scanning showed abnormal accumulation of leucocytes at 2 nd metatarsal bone with no significant accumulation at 4 th metatarsal. Both sites proved to be osteomyelitis. 


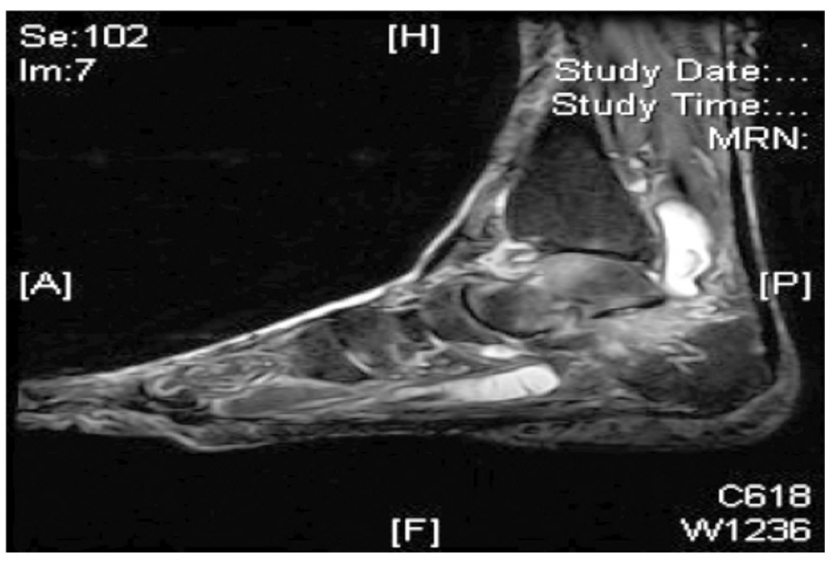

(A)

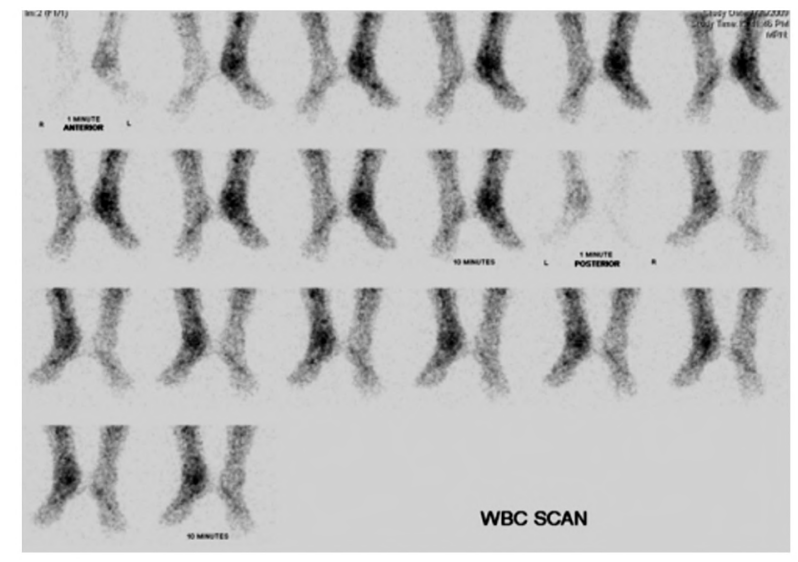

(B)

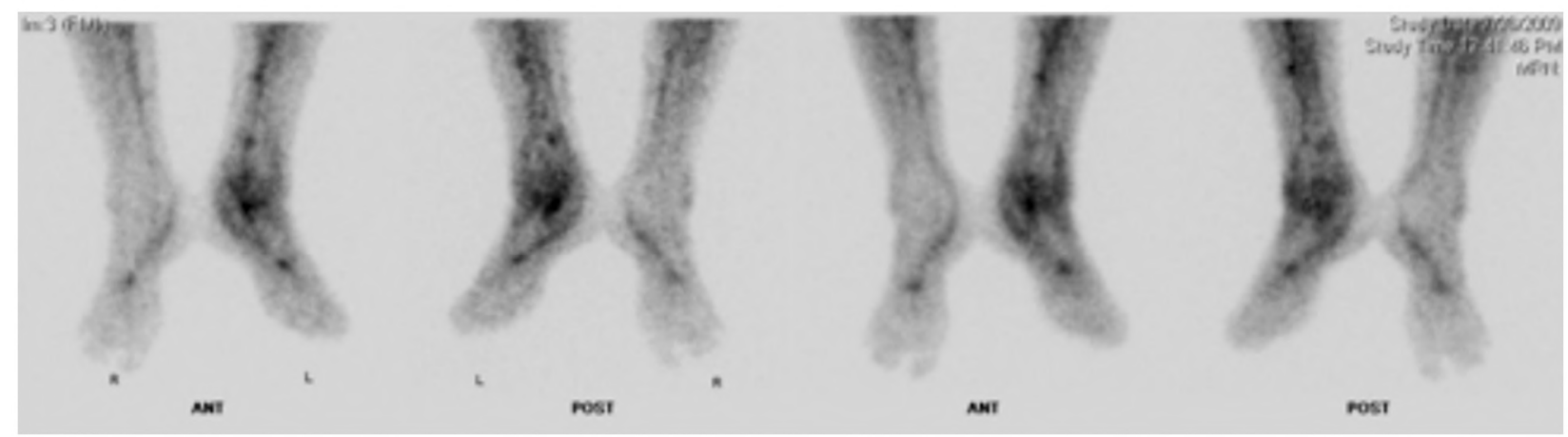

(c)

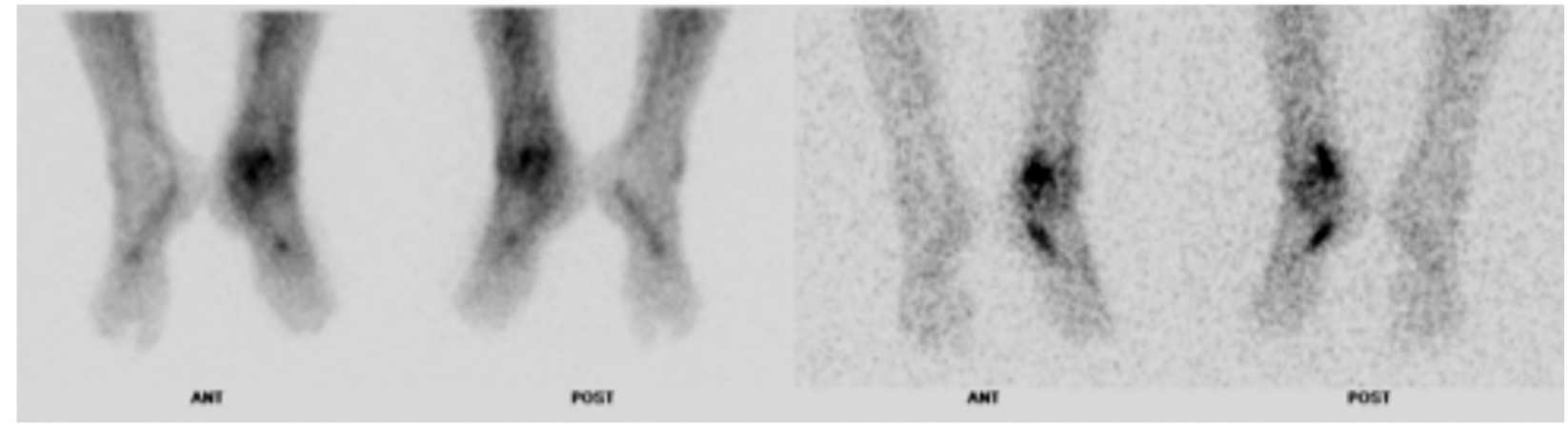

Fig. (2): Ulcer and infection around left ankle joint in a diabetic patient. Sagittal T2W fat suppressed image (A) Shows localized fluid collections at the posterior and anterior aspects of the ankle joint, around the tibiotalar articulation and within the planter subcutaneous tissues of the foot surrounded by soft tissue edema. Diffuse abnormal mottled bright marrow signal of the talus. Early dynamic (B) and static $30 \mathrm{~min}$, 2, 4 and 24 hours labeled leucocyte scanning showing abnormal accumulations corresponding to the localized fluid collections as well as the talar marrow signal abnormality. The latter turned out to be osteomyelitis. 


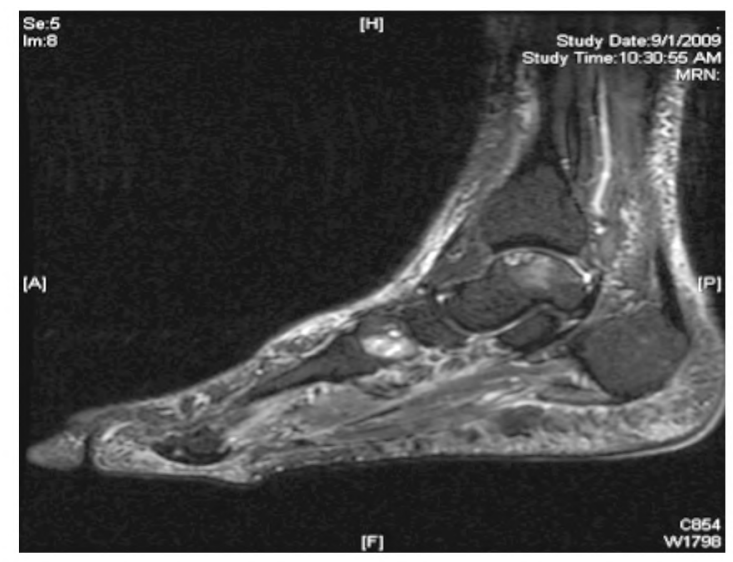

(A)

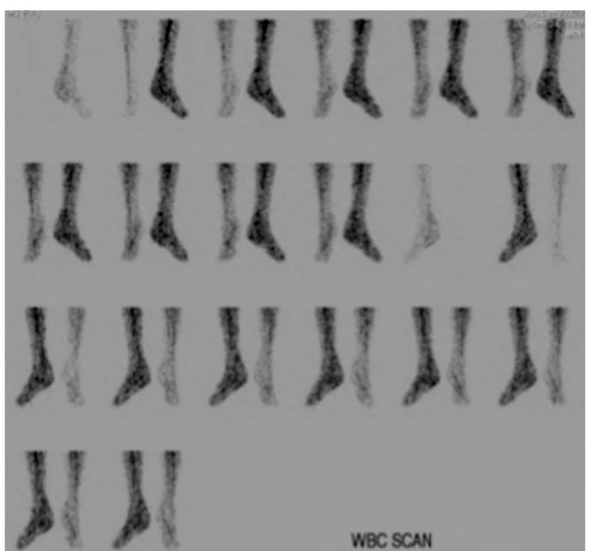

(B) Early dynamic views.

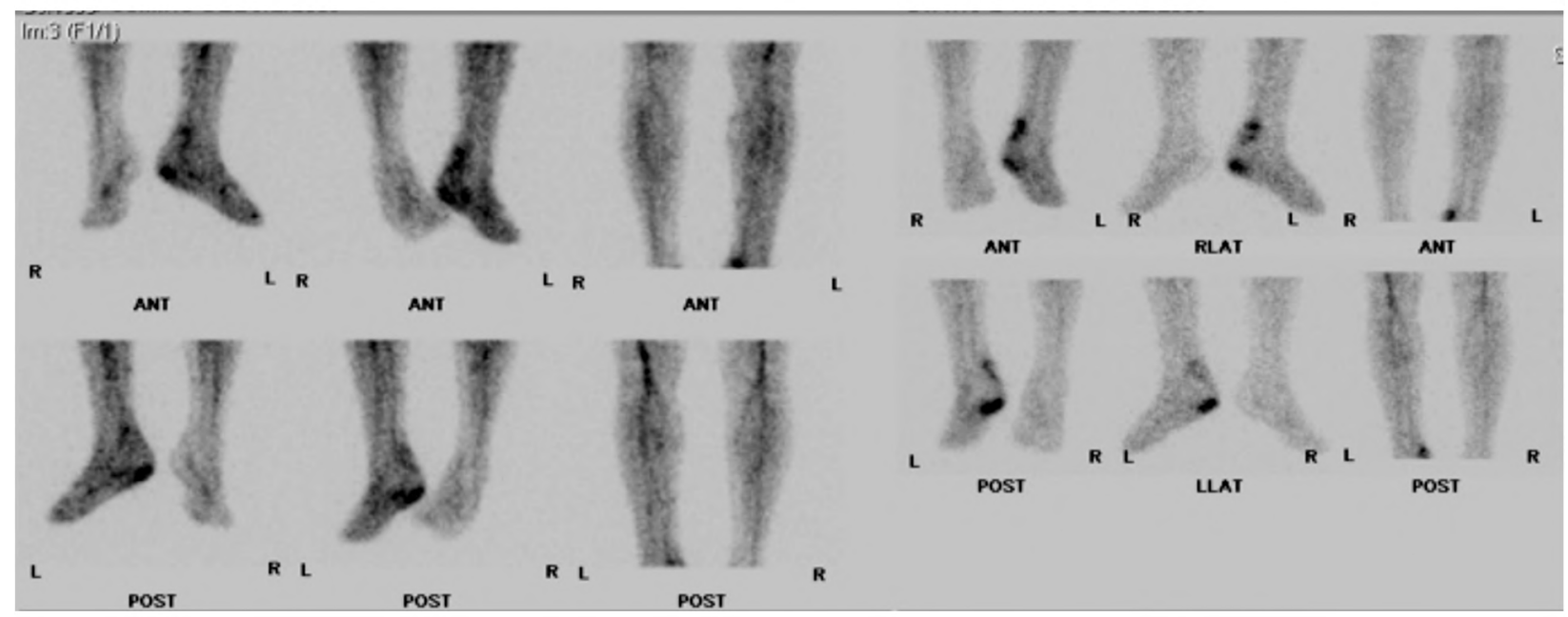

(C): Static views.

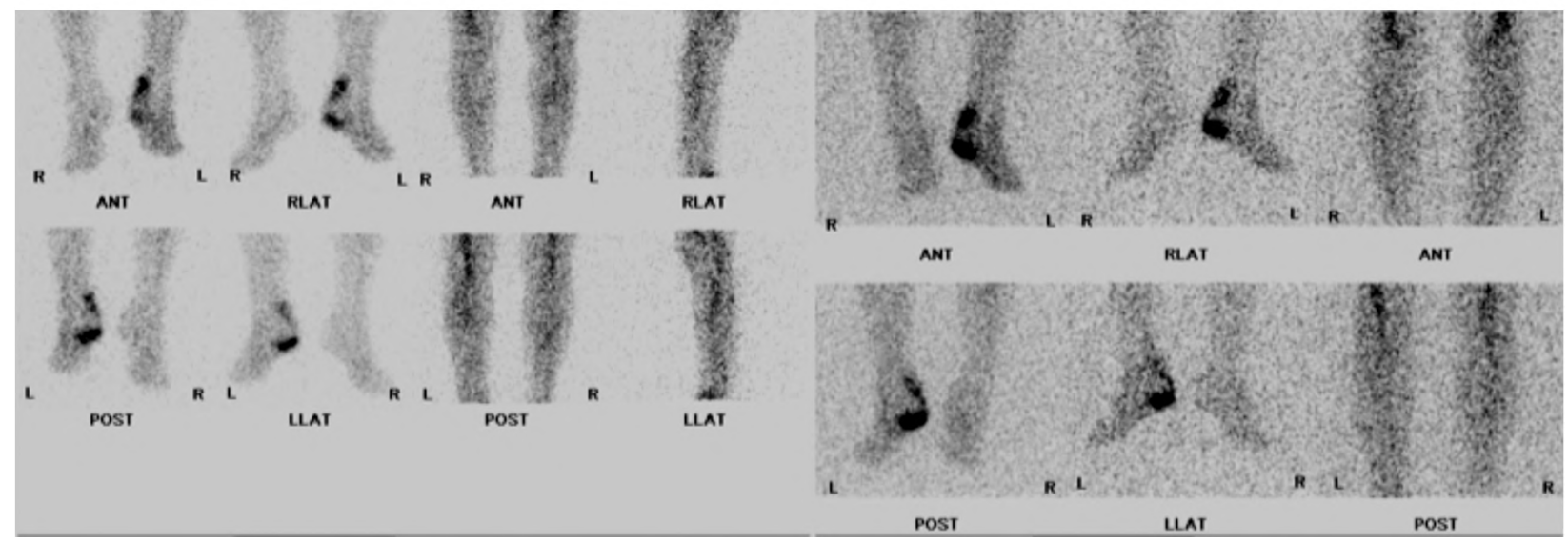

(D)

Fig. (3): Cellulitis and acute neuropathic disease in a diabetic patient. (A) Sagittal fat suppressed T2W images showed diffuse skin thickening and abnormal bright signal of the soft tissues at the dorsal aspect of the ankle joint and planter aspect of the foot. Abnormal bright marrow signal is the talar dome and the posterior portion of the medial cuneiform surrounding subchondral marginally sclerosed cysts. (B) Early dynamic and (C) and (D) Static labeled leukocyte scans showed abnormal leukocyte accumulation in the corresponding soft tissues and bone marrow areas of signal alteration. Increased bone marrow activity was observed in the first and second phases, whereas increased soft tissue activity without definite bone uptake was seen in the third phase. A decrease in leukocyte accumulation within the involved bone marrow areas in the follow-up scan indicated acute neuropathic changes. 
The sensitivity and specificity of MRI were (95\% and $85 \%$ ) and of labeled leucocyte scanning were $(87 \%$ and $90 \%)$ respectively. Therefore the combined use of 99mTc-HMPAO-LS and of MRI yielded higher sensitivity and specificity rates (Table 1). Inter-reader agreement was satisfactory (weighted kappa=0.676; 94\% CI, 0.490-0.882). There was disagreement for overall $11 \%$ of lesions.

Osteomyelitis was excluded in 20 clinically suspicious infection sites, nine of which were diagnosed as cellulitis and eleven as neuropathic ulcers (Table 2). In both cellulitis and diabetes related edema MRI showed skin thickening and increased T2W signal within the subcutaneous tissues and hypointense reticulation of fat on $\mathrm{T} 1 \mathrm{~W}$ images. Contrast enhancement was a distinguishing feature of cellulitis that was not seen in diabetes related edema nor neuropathic disease.

Table (1): Comparison of MRI and labeled leucocyte scanning in terms of sensitivity and specificity.

\begin{tabular}{lccc}
\hline $\begin{array}{l}\text { Results for } \\
\text { osteomyelitis }\end{array}$ & $\begin{array}{c}\text { Magnetic } \\
\text { resonance } \\
\text { imaging }\end{array}$ & $\begin{array}{c}\text { Labeled } \\
\text { leucocyte } \\
\text { scanning }\end{array}$ & $\begin{array}{c}\text { Final diagnosis based } \\
\text { on histopathology and } \\
\text { follow-up for 6 months }\end{array}$ \\
\hline $\begin{array}{l}\text { True positive } \\
\text { False positive }\end{array}$ & 21 & 20 & 23 \\
True negative & 17 & 2 & 20 \\
$\begin{array}{l}\text { False negative } \\
\text { Total }\end{array}$ & 2 & 3 & \\
Sensitivity & $95 \%$ & $87 \%$ & \\
Specificity & $85 \%$ & $90 \%$ & \\
\hline
\end{tabular}

Table (2): The final diagnosis of the 43 lesions based on histopathological examination and follow-up studies.

\begin{tabular}{lc}
\hline Final diagnosis & Number \\
\hline Osteomyelitis & 23 \\
Neuropathic ulcer & 11 \\
Cellulitis & 9 \\
\hline
\end{tabular}

\section{Discussion}

Osteomyelitis of the foot is a life-threatening complication in diabetic patients [7,9] and its diagnosis is often a difficult mission [10]. Major problems include differentiating soft-tissue from bone infection and infectious from non-infectious bone disorders [9]. Non-infectious disorders have been given many names, including Charcot's joint and neuro-osteoarthropathy, but are most simply referred to as osteopathy [11]. Once patients have a foot infection, it is difficult to distinguish chronic osteopathy, superficial soft-tissue infection and osteomyelitis either by clinical examination or diagnostic tests [10]. Bone biopsy is the gold stand- ard for the diagnosis of osteomyelitis [9]. Several imaging techniques have been widely used in diagnosis and differentiation of diabetes related foot complications $[\mathbf{9 , 1 2 , 1 3}$

The MRI-based diagnosis of osteomyelitis hinged on identification of abnormal bone marrow signals, typified by hypointensity on T1-weighted images and hyperintensity on fluid sensitive images as well as positive enhancement in the post contrast series. Although T2-weighted images are considered the most sensitive, it is the abnormal T1-weighted signal that is more indicative of osteomyelitis because the loss of the fatty marrow signal represents true infiltration of the bone by the infectious process [14-16]. Detection of bone marrow edema by MRI can occur before there is bone destruction and account for the increased sensitivity of MRI in diagnosing acute osteomyelitis compared to radiographic techniques. Specificity is more problematic as reactive bone marrow edema occurs in many conditions other than osteomyelitis such as overuse syndromes, gout and neuropathic osteoarthropathy [2-16-17]

Leukocyte scans may be accurate for the diagnosis of osteomyelitis and arthritis after an abnormal bone scan finding were found. One to 3 days after the onset of symptoms of acute osteomyelitis, a triple-phase bone scan may show increased activity in the first two phases (angiographic and blood pool phases) and focal increased uptake in the late phase (2-3h). The combination with a leukocyte scan may result in higher sensitivity and specificity rates $[\mathbf{1 8 , 1 9 ]}$

The early stages of neuroarthropathy are identified on MRI as soft tissue edema, fluid collections, effusions, and bone marrow abnormalities identical to those found in acute osteomyelitis $[\mathbf{2 0 , 2 1 ]}$. Periarticular soft tissue and bone marrow enhancement are observed by contrast enhanced MRI [22]. In the subacute stages bone resorption is a common finding. In the chronic stage, bone deformity, osseous fragmentation, and joint effusion may be also observed in MRI, with little marrow edema $[23,24]$

Several MRI features have been used for differentiating between these entities. Osteomyelitis develops almost exclusively contiguous to the skin ulcerations at predictable sites, namely distal to the tarsometatarsal joints, in the calcaneus and malleolus. Whereas neuropathic arthropathy is primarily periarticular and most commonly affects the tarsometatarsal and metatarsophalangeal joints. The midfoot presents the greatest diagnostic diffi- 
culty, although secondary signs of infection such as direct spread from an ulcer over a rocker-bottom deformity and the presence of a sinus tract are indicative of osteomyelitis $[14,25,26]$

Radionuclide studies are generally used as the complementary methods to MRI in the diagnosis of acute neuroarthropathy. The routine triple-phase bone scan is used as an initial step owing to its low specificity. Leukocyte-labeled scintigraphic studies enable the exclusion of osteomyelitis in the presence of a positive bone scan. However, the leukocyte scan may be positive in the early stages of diabetic neuroarthropathy owing to joint effusion induced by periarticular microfractures. A decrease in leukocyte accumulation within the involved area in the follow-up scan indicates acute neuropathic changes [18].

In our study, the definitive diagnosis was based on histopathological examination in 27 ulcer sites and follow-up studies in 16 sites. Our findings have shown sensitivities and specificities $(95 \%$ and $85 \%$ ) for MRI and (87\% and $90 \%$ ) for scintigraphy. In a meta-analysis by Eckman et al., [10] the sensitivity and specificity rates of labelled leucocyte scanning were deter-mined as $86 \pm 5.9 \%$ and $45 \pm 8.9 \%$, and of MRI as $99 \%$ and $71 \%$, respectively. In a review by Lipsky [1], the sensitivity and specificity rates of MRI ranged between 29 and $100 \%$ and 71 and $100 \%$, respectively. The main technical limitations of MRI is the relatively poor resolution for the cortex, which may cause some false-negative results in cases of isolated cortical infection. The typical marrow signal changes of osteomyelitis detected by MRI can be detected in any process that results in marrow replacement or infiltration, including osteoarthropathy. These technical difficulties with MRI will adversely influence sensitivity and specificity rates. Eckman et al., [10] also per-formed a cost-effectiveness analysis and concluded that non-invasive testing adds significant expense for patients in whom osteomyelitis is suspected and may result in little improvement in health outcomes.

Several studies, including one conducted by the American College of Radiologists Study Group, underlined the usefulness and value of MRI in the evaluation of diabetes-related foot complications and its accuracy for detecting osteomyelitis even in the presence of neuropathic arthropathy [25]. It has been recommended that MRI should be the first modality of choice in diabetic patients with soft tissue swelling without an apparent skin ulcer, followed by leukocyte-labeled scintigraphy $[27,28]$

\section{Conclusion:}

In conclusion, combining 99mTc-HMPAO labelled leucocyte scintigraphy with MRI was found to be an excellent method for the diagnosis of osteomyelitis in the diabetic foot. It can contribute to follow-up, particularly when clinical regression of perforating ulcers is incomplete and cure of osteomyelitis must be confirmed in order that antibiotic treatment may be discontinued.

\section{References}

1- LAM D. and LeROITH D.: The worldwide diabetes epidemic. Curr. Opin. Endocrinol. Diabetes Obes., 19: 936, 2012.

2- ROUG I.K. and PIERRE-JEROME C.: MRI spectrum of bone changes in the diabetic foot. Eur. J. Radiol., 81: 16259, 2012.

3- MAYANK MAHENDRA1 and RAHUL SINGH2: Diagnostic Accuracy and Surgical Utility of MRI in Complicated Diabetic Foot, J. Clin. Diagn. Res., Jul., 11 (7): RC01-RC04, 2017.

4- RICHARD J.L., LAVIGNE J.P. and SOTTO A.: Diabetes and foot infection: More than double trouble. Diabetes Metab. Res. Rev., 28: S4653, 2012.

5- BRIDGES R.M. Jr. and DEITCH E.A.: Diabetic foot infections. Pathophysiology and treatment. Surg. Clin. North Am., 74: 537-55, 1994.

6- HILL S.L., HOLTZMAN G.I. and BUSE R.: The effects of peripheral vascular disease with osteomyelitis in the diabetic foot. Am. J. Surg., 177: 282-6, 1999.

7- ERTUGRUL M.B.1, BAKTIROGLU S., SALMAN S., UNAL S., AKSOY M., BERBEROGLU K. and CALANGU S.: The diagnosis of osteomyelitis of the foot in diabetes: Microbiological examination vs. magnetic resonance imaging and labelled leucocyte scanning. Diabet. Med., (6); 23: 649-53, 2006.

8- LIPSKY B.A., BERENDT A.R., CORNIA P.B., PILE J.C., PETERS E.J., ARMSTRONG D.G., DEERY H.G., EMBIL J.M., JOSEPH W.S., KARCHMER A.W., PINZUR M.S. and SENNEVILLE E.: Infectious Diseases Society of America Clinical Practice Guideline for the Diagnosis and Treatment of Diabetic Foot Infections. J. Am. Podiatr. Med. Assoc., Jan.-Feb., 2013, 103 (1): 2-7, 2012.

9- LIPSKY B.A.: Osteomyelitis of the foot in diabetic patients. Clin. Infect. Dis., 25: 1318-26, 1997.

10- ECKMAN M.H., GREENFIELD S., MACKEY W.C., WONG J.B., KAPLAN S., SULLIVAN L., et al.: Foot infections in diabetic patients. Decision and cost effectiveness analyses. JAMA, 273: 712-20, 1995.

11- LIPSKY B.A., PECORARO R.E. and WHEAT L.J.: The diabetic foot. Soft tissue and bone infection. Infect Dis. Clin. North Am., 4: 409-32, 1990.

12- TOMAS M.B., PATEL M., MARWIN S.E. and PALESTRO C.J.: The diabetic foot. Br. J. Radiol., 73: 443$50,15,2000$.

13- NEWMAN L.G., WALLER J., PALESTRO C.J., SCHWARTZ M., KLEIN M.J., HERMANN G., et al.: 
Unsuspected osteomyelitis in diabetic foot ulcers. Diagnosis and monitoring by leukocyte scanning with indium in 111 oxyquinoline. JAMA, 266: 1246-51, 1991.

14- DONOVAN A. and SCHWEITZER M.E.: Current concepts in imaging diabetic pedal osteomyelitis. Radiol. Clin. North Am., 46: 110524, 2008.

15- LEDERMANN H.P., MORRISON W.B. and SCHWEITZER M.E.: MR image analysis of pedal osteomyelitis: Distribution, patterns of spread, and frequency of associated ulceration and septic arthritis. Radiology, 223: 74755, 2002.

16- SCHWEITZER M.E. and MORRISON W.B.: MR imaging of the diabetic foot. Radiol. Clin. North Am., 42: 6171, 2004.

17- TOLEDANO T.R., FATONE E.A., WEIS A., COTTEN A. and BELTRAN J.: MRI evaluation of bone marrow changes in the diabetic foot: A practical approach. Semin. Musculoskelet. Radiol., 15: 25768, 2011.

18- LOREDO R., RAHAL A., GARCIA G. and METTER D.: Imaging of the diabetic foot diagnostic dilemmas. Foot Ankle Spec., 3: 24964, 2010.

19- TRONCO G., TOMAS M. and PALESTRO C.: Fourphase bone scintigraphy and osteomyelitis: A reevaluation. Clin. Nucl. Med., 24: 216, 1992.

20- MARCUS C.D., LADAM-MARCUS V.J., LEONE J., MALGRANGE D., BONNET-GAUSSERAND F.M. and MENANTEAU B.P.: MR imaging of osteomyelitis and neuropathic osteoarthropathy in the feet of diabetics. Radiographics, 16: 133748, 1996.
21- MORRISON W.B. and LEDERMANN H.P.: Work-up of the diabetic foot. Radiol. Clin. North Am., 40: 117192, 2002.

22- YUH W.T., CORSON J.D., BARANIEWSKI H.M., REZAI K., SHAMMA A.R., KATHOL M.H., et al.: Osteomyelitis of the foot in diabetic patients: Evaluation with plain film, 99mTc-MDP bone scintigraphy, and MR imaging. A.J.R. Am. J. Roentgenol., 152: 795800, 1989.

23- BROWER A.C. and ALLMAN R.M.: Pathogenesis of the neurotrophic joint: Neurotraumatic vs. neurovascular. Radiology, 139: 34954, 1981.

24- CLOUSE M.E., GRAMM H.F., LEGG M. and FLOOD T.: Diabetic osteoarthropathy. Clinical and roentgenographic observations in 90 cases. Am. J. Roentgenol. Radium. Ther. Nucl. Med., 121: 2234. 4, 1974.

25- KAPOOR A., PAGE S., LaVALLEY M., GALE D. and FELSON D.: Magnetic resonance imaging tor diagnosing foot osteomyelitis. Arch. Intern. Med., 167: 12532, 2007.

26- TAN P.L. and TEH J.: MRI of the diabetic foot: Differentiation of infection from neuropathic change. Br. J. Radiol., 80: 939-48, 2007.

27- PALESTRO C. and LOVE C.: Nuclear medicine and diabetic foot infections. Semin. Nucl. Med., 39: 5365 , 2009.

28- SCHWEITZER M.E., DAFFNER R.H., WEISSMAN B.N., BENNETT D.L., BLEBEA J.S., JACOBSON J.A., et al.: ACR Appropriateness Criteria on suspected osteomyelitis in patients with diabetes mellitus. J. Am. Coll. Radiol., 5: 8816, 2008. 


\section{التصوير بالرئين المغناطيسى والتكنيتيوم 99م سلاسى ميثيل البروبيلين أمين

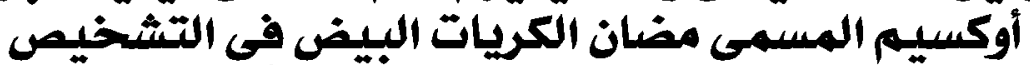 والتمييز بين إلتهاب العظم والنقى الحاد واعتلال الأعصاب فى التصى القدم السكرية}

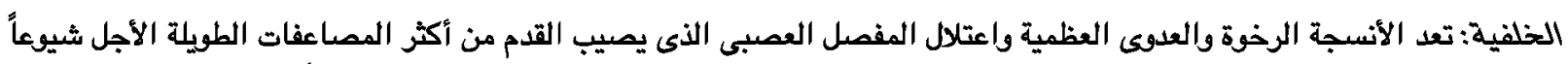

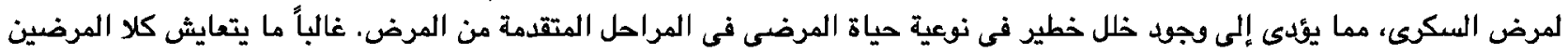

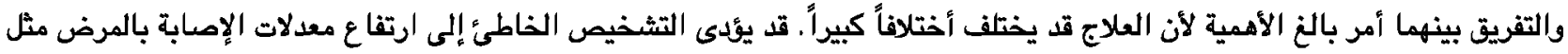
بتر الأطراف غير الضرئه أهر بالغ الأهع.

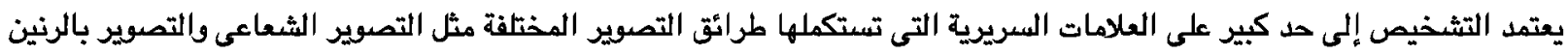
المغناطيسى وتقنيات التصوير الهجينة مثل التصوير المقطعى بالإصدار البوزيترونى الفلوروكسيكلوكونونفزيتر 18 والتصوير النويى ودراسات التصوير النونى.

الهدف من الدراسة: الهدف من هذه الدراسة هو تقييم القيمة التشخيصية التصوير بالرنين المغناطيسى والتناسل 99 مليون هيكساميثيل

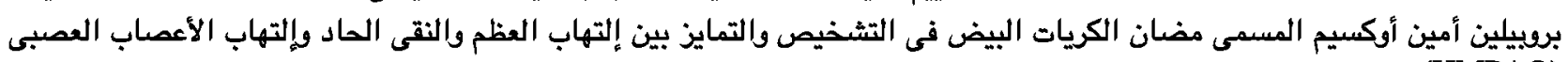

(HMPAO)

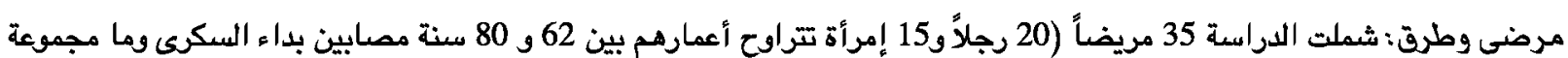

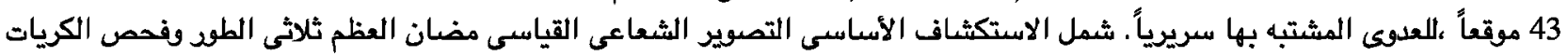

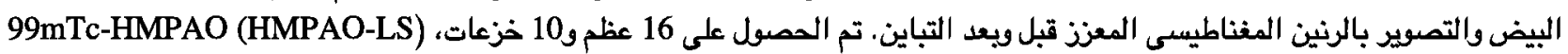

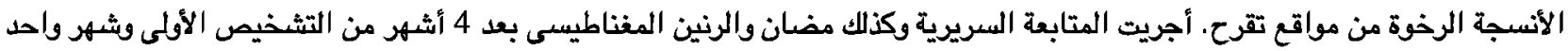
بعد انسحاب المضادات الميوية فى حالات إلتهاب العظم والنقى المشتبه بهم.

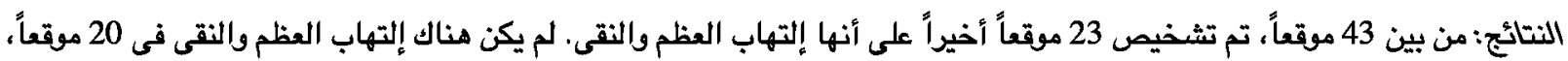

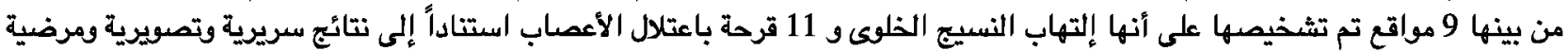

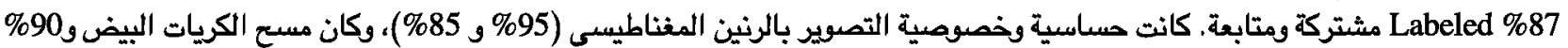
على التوالى.

الخلاصة: وقد أسفر الاستخدام المشترك بالرنين المغناطيسى والتكنيتيوم 99 م سداسى ميثيل البروبيلين أمين أوكسيم المسمى مضان

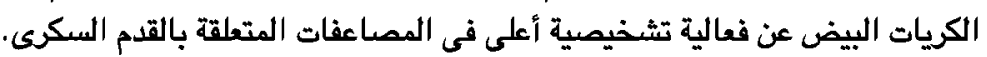

